\title{
Hard driven but not dishonest: Cheating and the Type A personality
}

\author{
MATTHEW T. HUSS, JOHN P. CURNYN, SHARON L. ROBERTS, and STEPHEN F. DAVIS \\ Emporia State University, Emporia, Kansas \\ and \\ LONNIE YANDELL and PETER GIORDANO \\ Belmont University, Nashville, Tennessee
}

\begin{abstract}
Two hundred twenty college students volunteered to complete questionnaires to measure Type A behavior, academic dishonesty, and classroom orientation. The present data replicated and extended a previous report (Weiss, Gilbert, Giordano, \& Davis, 1993) by showing that learning orientation, lower levels of academic dishonesty, and Type A characteristics were positively related. Conversely, grade orientation, Type B characteristics, and higher levels of academic dishonesty were positively related.
\end{abstract}

Because high achievement motivation is an important characteristic of the Type A individual (Carver \& Humphries, 1982) and because individuals with high achievement motivation are more prone to cheat in college (Johnson, 1981), one might expect Type A students to display higher rates of cheating than their Type B counterparts. Lending support to this prediction, Perry, Kane, Bernesser, and Spicker (1990) reported that Type A college students were more likely to cheat on a word-forming task than were Type B students. This tendency was shown under both competitive and noncompetitive conditions.

In a more direct test of exam cheating, Weiss, Gilbert, Giordano, and Davis (1993) evaluated the relationship between Type A behavior and cheating on college examinations. Contrary to the results reported by Perry et al. (1990), Weiss et al. (1993) reported that Type A behavior was negatively related to academic dishonesty. Additionally, it was shown that Type A behavior was positively related to a learning orientation (as opposed to a grade orientation) in the classroom.

Since the Weiss et al. (1993) data were gathered at a small, private liberal arts institution, it seemed relevant to replicate these results at an institution of a different nature. Davis, Grover, Becker, and McGregor (1992) reported differences in cheating rates between small, private liberal arts institutions and large institutions--thus, the importance of such a replication is highlighted. Perhaps the relationship between academic dishonesty, classroom orientation, and Type A behavior would be different at a larger institution where self-reported cheating rates

Correspondence may be addressed to L. Yandell or P. Giordano, Department of Behavioral Sciences, Belmont University, 1900 Belmont Blvd., Nashville, TN 37212-3757, or to S. F. Davis, Department of Psychology, Emporia State University, Emporia, KS 66801-5087. are typically greater. Thus, the present replication/extension was conducted at a larger, state university. Additionally, since Weiss et al. (1993) did not evaluate gender effects, consideration of this factor also was incorporated into the present project.

\section{METHOD}

\section{Subjects}

The subjects consisted of 220 undergraduate student volunteers $(78$ men, 142 women) enrolled at a regional, midwestern state university.

\section{Testing Instruments}

Academic dishonesty was measured by a seven-item questionnaire (Weiss et al., 1993). This questionnaire requested information about frequency of cheating in high school (Question 1), frequency of cheating in college (Question 2), fear of being caught cheating (Question 3), improvement of scores via cheating (Question 4), the influence of strict penalties (Question 5), effective penalties (Question 6), and reasons for cheating (Question 7).

The modified Jenkins Activity Survey (JAS; see Krantz, Glass, \& Snyder, 1974), a 21-item questionnaire, was used to measure Type A/B behavior. The LOGO II (Eison, 1981; Eison \& Pollio, 1989), a 32item Likert-type scale, was used to evaluate grade orientation and learning orientation.

The three testing instruments and a demographic sheet, requesting gender, age, classification, and work hours, were combined to form a self-administering questionnaire packet. The demographic sheet was always the top sheet, followed by the LOGO II and JAS. The LOGO II and JAS questionnaires alternated in sequence of appearance in order to preclude order effects. Because it was potentially the most threatening instrument, the academic dishonesty questionnaire always appeared at the end of the packet. The two different packet versions created by the arrangement of the LOGO II and the JAS were alternately sorted prior to distribution.

\section{Procedure}

The subjects were given an informed consent form and a questionnaire packet during a regularly scheduled class session. The experimenter explained the informed consent form prior to completion of any questionnaires. Although no time limit was imposed, all subjects completed the questionnaire packet within $20 \mathrm{~min}$. To ensure anonymity, the questionnaire packets and informed consent forms were collected separately. 


\section{RESULTS AND DISCUSSION}

Analysis of the demographic data indicated that the average age of the men was 22.42 years $(S D=4.09$, range $=19-42)$, and the average age of the women was 21.41 years $(S D=4.08$, range $=18-56)$. The selfreported high school and college cheating rates of these subjects are as follows: of the men, $77 \%$ reported cheating in high school and $50 \%$ reported cheating in college; of the women, $73 \%$ reported cheating in high school and $40 \%$ reported cheating in college. These data are in accord with the high school and college cheating rates reported by Davis et al. (1992). However, the college rates stand in marked contrast to the $16 \%$ college cheating rate reported by Weiss et al. (1993). As noted by Davis et al., this differential is likely attributable to institution size and type. They reported that the lowest academic dishonesty rates occurred at small, private liberal arts institutions, such as the one where the Weiss et al. data were gathered. Conversely, the present data were gathered at a larger, public institution.

Correlation coefficients relating Type A characteristics, classroom orientation, and cheating behavior for the men and women are shown in Table 1 . In all instances, twotailed tests of significance and an alpha level of .05 were employed.

The present report provides a convincing replication of the Weiss et al. (1993) data. More specifically, significant, positive correlations existed between Type $\mathrm{A}$ behavior and learning orientation and between cheating and grade orientation. Conversely, significant negative correlations existed between Type $\mathrm{A}$ behavior and grade orientation and between cheating and learning orientation. Thus, while Type A individuals may be hard driven and competitive, they do not seek to achieve their educational goals via unauthorized means. In fact, their lower levels of academic dishonesty, coupled with their learning orientation, should make them both desirable and effective students.

The present study also extends the Weiss et al. (1993) data in important ways. First, the fact that comparable results were shown by men and women indicates that the previous results were not gender dependent. Second, the demonstration of comparable results at a larger, public institution extends the generality of the Weiss et al. findings. The fact that different percentages of self-reported cheating were observed at these two institutions indicates

Table 1

Correlation Coefficients for Type A Characteristics, Cheating, Learning Orientation (LO), and Grade Orientation (GO)

\begin{tabular}{|c|c|c|c|c|c|c|c|c|}
\hline & \multicolumn{4}{|c|}{ Men } & \multicolumn{4}{|c|}{ Women } \\
\hline & Type A & Cheat & LO & GO & Type A & Cheat & LO & GO \\
\hline $\begin{array}{l}\text { Type A } \\
\text { Cheat } \\
\text { LO } \\
\text { GO }\end{array}$ & - & $\begin{array}{c}-.12 \\
-\end{array}$ & $\begin{array}{r}.29 * \\
-.26 \dagger \\
-\end{array}$ & $\begin{array}{r}-.24 \dagger \\
.38 \ddagger \\
-.47 \ddagger \\
-\end{array}$ & - & $\begin{array}{c}-.06 \\
-\end{array}$ & $\begin{array}{r}.28 \ddagger \\
-.20 \dagger \\
-\end{array}$ & $\begin{array}{r}-.23 * \\
.20 \dagger \\
-.27 \ddagger \\
-\end{array}$ \\
\hline
\end{tabular}

that the relations reported in these two studies are not influenced by the percentage of students who admit to cheating.

Clearly, the present data and those reported by Weiss et al. (1993) stand in marked contrast to the Perry et al. (1990) findings that Type A students were more prone to cheat on a word-forming task where prior preparation was impossible. Why the discrepancy? It is tempting to speculate that the ability to exercise control may be responsible. In the Perry et al. study subjects were able to exercise less control over their performance than the typical college student can exercise over his/her grades. Lacking the ability to prepare adequately, the Type A students in the Perry et al. study resorted to cheating to maintain the desired high performance levels. The significant, positive relationship between Type A characteristics and learning orientation would seem to support this contention. Learning is an endeavor that is under one's control; one does not need to cheat to achieve this goal. In fact, cheating is antithetical to learning.

There is one additional interpretation for this discrepancy. A major difference between the Perry et al. (1990) data and the results of the present study and the Weiss et al. (1993) study concerns how cheating was measured. Many people, perhaps even Type A and learningoriented individuals, are reluctant to admit that they would or have cheated. Given the right circumstances, individuals may cheat but not admit it to others or themselves. Perhaps Type A students would never admit that they have cheated or admit to themselves that they would ever cheat in the future. Perry et al. may have created the circumstances to encourage cheating. One such circumstance may indeed be the lack of control. However, lacking supportive data, such speculations await experimental verification.

\section{REFERENCES}

Carver, C. S., \& Humphries, C. (1982). Social psychology and the Type A coronary-prone behavior pattern. In G. S. Sanders \& J. Suls (Eds.), Social psychology of health and illness. Hillsdale, NJ: Erlbaum. Davis, S. F., Grover, C. A., Becker, A. H., \& McGregor, L. N. (1992). Academic dishonesty: Prevalence, determinants, techniques, and punishments. Teaching of Psychology, 19, 16-20.

Eison, J. (1981). A new instrument for assessing students' orientation towards grades and learning. Psychological Reports, 48, 919-924.

EISON, J., \& Pollo, H. (1989). LOGO II: Bibliographic and statistical update. Cape Girardeau, MO: Southeast Missouri State University, Center for Teaching and Learning.

JoHnson, P. B. (1981). Achievement motivation and success: Does the end justify the means? Journal of Personality \& Social Psychology, 40, 374-375.

Krantz, D. S., Glass, D. C., \& SNyder, M. L. (1974). Helplessness, stress level, and the coronary-prone behavior pattern. Journal of Experimental Social Psychology, 10, 284-300.

Perry, A. R., Kane, K. M., Bernesser, K. J., \& SPicker, P. T. (1990). Type A behavior, competitive achievement-striving, and cheating among college students. Psychological Reports, 66, 459-465.

Weiss, J., Gilbert, K., Giordano, P., \& Davis, S. F. (1993). Academic dishonesty, Type A behavior, and classroom orientation. Bulletin of the Psychonomic Society, 31, 101-102.

(Manuscript received April 26, 1993.) 